\title{
Prevalence of pain awareness, treatment, and associated health outcomes across different conditions in Brazil*
}

\section{Prevalência da percepção e do tratamento da dor e de seus resultados de saúde em diferentes condições do Brasil}

Amir Goren, PhD; Hillary Johanna Gross, MPH²; Ronaldo Kenzou Fujii, PhD; Abhishek Pandey, MD; Joaquín Mould-Quevedo, MSc, MBA, PhD4

* Received from Pfizer Inc. New York, NY.

\section{SUMMARY}

BACKGROUND AND OBJECTIVES: Pain is a prevalent clinical condition causing tremendous humanistic and economic burden worldwide. With limited research into the impact of pain on health related outcomes in Brazil, the current study examined prevalence of pain conditions, rate of diagnosis and treatment, and potential impact on health outcomes among Brazilian adults.

METHOD: Data were collected from the stratified random sample of adults $(\mathrm{n}=12,000)$ in thecross-sectional 2011 National Health and Wellness Survey (NHWS) in Brazil. Respondents reported on sociodemographic information, health-related quality oflife(SF-12v2), work productivity and activity impairment (WPAI), comorbid conditions, and healthcare resource use. Comparisons between those reporting pain and no pain (i.e.,neuropathic pain, fibromyalgia, surgery/medical procedurerelated pain, or back pain, versus controls without the respective condition; or arthritis, with vs. without experiencing pain) were conducted using Chi-square and t-tests for categorical and continuous variables, respectively.

RESULTS: Back pain was the most commonly reported

1. Kantar Health, New York, NY.

2. Kantar Health, Princeton, NJ.

3. Pfizer, Inc., São Paulo, Brazil.

4. Pfizer, Inc., New York, NY.

Address correspondence:

Amir Goren, PhD.

Kantar Health

11 Madison Ave, $12^{\text {th }}$ Floor

New York, NY 10010

Phone: 1-212-706-3909 - Fax: 1-212-647-7659

E-mail: amir.goren@kantarhealth.com pain condition ( $12 \%$ ), followed by fibromyalgia. Among those experiencing the condition neuropathic pain was the most, and back pain the least, commonly diagnosed and treated. Across conditions, to varying degrees, pain vs. no pain was associated with greater comorbid burden, higher resource utilization, and greater impairments in health status and work productivity, with few differences in sociodemographic factors.

CONCLUSION: Pain-related conditions were associated with varying awareness and treatment rates among Brazilian adults. Consistent with previous US and European studies, pain was associated with various negative health outcomes. These findings highlight the under-treatment and range of potential sources of pain burden in Brazil.

Keywords: Back pain, Brazil, Pain burden, Quality of life, Work productivity.

\section{RESUMO}

JUSTIFICATIVA E OBJETIVOS: A dor é uma condição clínica prevalente que gera um fardo humanístico e econômico tremendo em todo o mundo. Tendo em vista os poucos estudos sobre o impacto da dor em resultados de saúde no Brasil, este estudo avaliou a prevalência de condições dolorosas, a taxa de diagnóstico e tratamento, e o possível impacto nos resultados de saúde entre adultos brasileiros.

MÉTODO: Os dados foram coletados de uma amostra estratificada e aleatória de adultos ( $\mathrm{n}=$ 12.000) da pesquisa transversal National Health and Wellness Survey de 2011 feita no Brasil. Os entrevistados deram informações sociodemográficas, sobre qualidade de vida relacionada à saúde (SF12v2), produtividade no trabalho e prejuízo de suas atividades (WPAI), condições comórbidas e uso de 
recursos de assistência à saúde. As comparações entre os indivíduos com e sem dor (isto é, dor neuropática, fibromialgia, dor relacionada a procedimentos cirúrgicos/médicos, ou lombalgia, versus os controles sem a respectiva condição; ou artrite, com versus sem dor) foram realizadas pelos testes Quiquadrado e $t$ para variáveis categóricas e contínuas, respectivamente.

RESULTADOS: Lombalgia foi a condição dolorosa mais comum (12\%), seguida de fibromialgia. Entre os incluídos nessa condição, a dor neuropática foi a mais comumente diagnosticada e tratada, e a lombalgia foi a menos diagnosticada e tratada. Nas dife rentes condições, em graus variáveis, dor versus sem dor foi associada a maior fardo comórbido, maior utilização de recursos, e maiores prejuízos ao estado de saúde e à produtividade no trabalho, com poucas diferenças nos fatores sociodemográficos.

CONCLUSÃ O: As condições dolorosas foram associadas a diferentes percepções e taxas de tratamento entre adultos brasileiros. Corroborando estudos anteriores norte-americanos e europeus, a dor foi associada a vários resultados negativos para a saúde. Esses achados destacam o subtratamento e uma gama de fontes potenciais de fardo da dor no Brasil.

Descritores: Brasil, Fardo da dor, Lombalgia, Produtividade no trabalho, Qualidade de vida.

\section{INTRODUCTION}

Pain is a highly prevalent, debilitating clinical condition responsible for tremendous humanistic and economic burden throughout the world ${ }^{1-3}$. Prevalence rates vary based on the type of pain and timeframe assessed, with chronic non-cancer pain reported by $5 \%-20 \%$ of survey samples ${ }^{4-7}$, lower back pain reported by nearly $30 \%^{8}$, and higher rates frequently reported among those diagnosed with conditions such as cancer ${ }^{9}$. Chronic pain affects more Americans than heart disease, cancer, and diabetes combined ${ }^{10,11}$ and is the most frequent reason for individuals to seek care from a health care provider. In the U.S., a recent report by the Institute of Medicine estimated direct health care costs associated with chronic pain to be between $\$ 261$ and $\$ 300$ billion, with a further $\$ 297$ to $\$ 336$ billion associated with lost productivity and absenteeism. Importantly, pain conditions are often associated with comorbid illness, heightened psychological distress, and impaired quality of life across a number of domains ${ }^{12-15}$.

Pain can manifest from a variety of sources or conditions and is most frequently classified as acute or chronic in nature, with chronic pain representing a condition that has persisted beyond normal healing time ${ }^{16}$. A variety of treatment modalities exist for the treatment of pain, including prescription and nonprescription medication, surgicalprocedures, and nonpharmacological approaches (psychologically-based interventions). Pain medications can be classified as opioid, nonopioid or adjuvant analgesics. Opioid analgesics (such as morphine) represent the gold standard in the management of moderate to severe pain, while nonopioid analgesics (such as aspirin, acetaminophen) can be used individually for mild to moderate pain, or in conjunction with opioid analgesics for more severe pain.

Given the prevalence of pain reported by individuals, a number of important issues have arisen in the pharmacological treatment of pain conditions. Opioid analgesics possess addictive qualities; therefore, extensive research examines their long-term use and effectiveness in the treatment of chronic pain conditions ${ }^{17}$. It has been argued that the widespread concern regarding the prescribing of opioid medications, particularly in the context of chronic pain, may have resulted in the under-treatment of severe pain in other clinical contexts, such as cancer ${ }^{18,19}$.

The majority of research in this domain has examined prevalence rates of pain in the U.S. and Europe, where treatment models exist within the context of their respective health care systems. A paucity of research has examined the prevalence and treatment of pain elsewhere in the world. This is of critical importance given the role that culture can play in the reporting of pain and provision of care ${ }^{20}$ both within country, and especially across countries.

Broader assessments of pain are lacking, for example, in Brazil, where published reports have focused on specific populations ${ }^{1}$ or comorbid conditions $^{22}$. One reported survey of adult workers identified a $61.4 \%$ prevalence rate of chronic pain, with higher rates reported by women ${ }^{23}$.

The current study contributes to the extant literature by examining the potential impact of pain on work productivity and health-related quality of life across a range of disease states commonly associated with pain (neuropathic pain, arthritis pain, fibromyalgia, back pain, and surgery/medical procedure-related pain) in Brazil. This analysis provides important information regarding the current state of pain management in this understudied region, raising awareness of barriers to seeking and improving care, by further examining rates of diagnosis and treatment. 


\section{METHOD}

\section{Sample and procedure}

Data were taken from the 2011 National Health and Wellness Survey (NHWS; Kantar Health, New York, NY, USA) in Brazil, an annual, cross-sectional survey using stratified random sampling based on age, sex, and socioeconomic status (SES) to be representative of the Brazil adult population ( $\geq 18$ years). Invitations to participate were sent to members of the Lightspeed Research Internet panel via email and the survey was administered online, while some respondents over the age of 50 years were recruited in person or on the phone and administered computer-assisted Web interviews (CAWI). Of the $\mathrm{N}=12,000$ respondents, $\mathrm{n}=10,636$ were completed online and $\mathrm{n}=1,346$ completed CAWIs. All participants gave explicit informed consent, and secondary consent forms were completed to allow for interviewer administration of CAWI. Institutional Review Board (IRB) approval was granted by Essex IRB (Lebanon, NJ), and the study is in compliance with the principles of the Declaration of Helsinki ${ }^{24}$. Results were weighted by gender, age, and SES (using the International Data Base of the U.S. Census Bureau and Organization for Economic Cooperation) so that projections matched the overall Brazilian population.

\section{Measures}

\section{Pain groups}

All participants were initially asked if they were experiencing certain medical conditions, including arthritis, fibromyalgia, and pain. The self-reported pain questions in the NHWS survey and its associated outcomes have been accepted as valid measures in different regions, including the European Union ${ }^{1,25}$. Past investigations analyzing the NHWS data have found the experience of pain, in particular severe daily pain, to have a substantial negative association with labor force participation in five European countries. Langley et al. ${ }^{25}$ have also found decreased health-related quality of life and increased provider visits, emergency room visits, and hospitalizations among those experiencing pain. Respondents choosing fibromyalgia or pain were asked to specify types of pain they experienced in the past month and severity for each type. In addition to these pain types, patients with diabetic neuropathy were included with neuropathic pain patients. Arthritis (i.e., rheumatoid arthritis or osteoarthritis) patients indicated physician diagnosis of their arthritis type and separately indicated whether theyexperienced arthritis-related pain in the past year. Pain types were categorized into five dichotomous groups for analysis: (1) experiencing neuropathic pain or diabetic neuropathy (collectively referred to as neuropathic pain) versus not; (2) diagnosed with arthritis and experiencing arthritis pain versus diagnosed and not experiencing arthritis pain; (3) experiencing fibromyalgia versus not; (4) experiencing back pain versus not; and (5) experiencing pain from a surgical or medical procedure versus not. Of the 12,000 respondents, $n=1,642$ experienced at least one of the pain conditions of interest. The groups were not exclusive of each other; a respondent could have more than one pain type.

\section{Demographics and health characteristics}

Gender, age, marital status, employment status, income, educational attainment, and SES (A1-A2 [upper class], B1B2 [middle class], C1 [lower middle class], C2 [skilled working class], D [lower working class], and E [lowest income earners] were assessed ${ }^{26}$. Body mass index (BMI), smoking status, alcohol use, exercise in the past month, and Charlson comorbidity index (CCI) were also assessed $^{27}$. The CCI calculates the comorbid burden by weighting several comorbidities by severity and summing the result.

\section{Health-related quality of life}

Health status was measured using the Brazilian Portuguese version of the Short-Form 12 (SF$12 \mathrm{v} 2)^{28,29}$. The SF-12v2 translation was provided by Quality Metric's process of independent forward and back translations, and this version was validated against other pain measures ${ }^{30,31}$. Physical Component Summary (PCS) and Mental Component Summary (MCS) scores, as well as the SF-6D health utilities index, were generated from the SF-12v2, with higher scores representing better health status. The SF-6D index varies on a theoretical scale of 0 to 1 , where 0 represents death and 1 represents perfect health.

\section{Work impairment}

Work impairment was captured via the Work Productivity and Activity Impairment (WPAI) questionnaire, a validated instrument containing four 
subscales ${ }^{32}$. The translated Brazilian version of the WPAI ${ }^{33}$ has been used in the past (i. e. for COPD patients) ${ }^{34}$. Absenteeism represents the percentage work time missed due to health in the past 7 days. Presenteeism represents impairment while at work due to health in the past 7 days Overall work impairment represents the total work time impaired or missed due to health in the past 7 days (derived from absenteeism and presenteeism). Absenteeism, presenteeism, and overall work impairment were assessed only for respondents employed full-time, part-time, or self-employed. Activity impairment represents the percentage impairment of daily activities outside work due to health in the past 7 days, and was assessed for all respondents.

\section{Healthcare resource utilization}

Healthcare utilization was measured by the self-reported number of physician visits, ER visits, and hospitalizations in the preceding six months. These measures were also dichotomized into yes (used the healthcare resource) versus no ratings.

\section{Statistical analyses}

Frequencies and percentages (for categorical variables) and means and standard deviations (for continuous variables) were reported for each measure. All results were weighted and projected to the Brazilian adult population. Respondents who did not self-report experiencing each pain type were compared against those with pain using Chi-square and t-tests for categorical and continuous variables, respectively.

The NHWS and associated consent form were approved by Essex IRB (Lebanon, NJ). All respondents had to provide their informed consent to participate in the study.

\section{RESULTS}

\section{Prevalence, diagnosis, and treatment}

Of the total sample $(\mathrm{n}=12,000 ; 137.9 \mathrm{M})$, $\mathrm{n}=1,642$ (projected $18.9 \mathrm{M}$ ) respondents reported experiencing pain: neuropathic pain $(n=41 ; 569 \mathrm{~K})$, diagnosed rheumatoid or osteoarthritis with arthritis pain $(\mathrm{n}=118 ; 1.3 \mathrm{M})$, fibromyalgia $(\mathrm{n}=253 ; 2.8 \mathrm{M})$, back pain $(\mathrm{n}=1,425 ; 16.8 \mathrm{M})$, or pain from surgery or medical procedure $(\mathrm{n}=107 ; 1.2 \mathrm{M}$; (Table 1). Back pain was most common (12.16\% of Brazilian adults), followed by fibromyalgia $(2.01 \%)$, neuropathic pain $(1.70 \%)$, rheumatoid or osteoarthritis pain $(0.97 \%)$, and surgery or medical procedure pain $(0.84 \%)$. Of

Table 1 - Prevalence of experiencing, diagnosis, and treatment of pain types.

\begin{tabular}{|c|c|c|c|c|c|}
\hline & Neuropathic Pain & $\begin{array}{c}\text { Arthritis \& } \\
\text { Arthritis Pain }\end{array}$ & Fibromyalgia & Back Pain & $\begin{array}{c}\text { Surgery/Medical } \\
\text { Procedure Pain }\end{array}$ \\
\hline & $569 K(n=41)$ & $1.3 \mathrm{M}(\mathrm{n}=118)$ & $2.8 \mathrm{M}(\mathrm{n}=253)$ & $16.8 \mathrm{M}(\mathrm{n}=1,425)$ & $1.2 \mathrm{M}(\mathrm{n}=107)$ \\
\hline \multicolumn{6}{|l|}{ Experiencing Pain } \\
\hline sample size (n) & 41 & 118 & 253 & 1425 & 107 \\
\hline projected & 568,726 & $1,341,776$ & $2,769,773$ & $16,768,465$ & $1,153,541$ \\
\hline $\begin{array}{l}\text { projected } \% \\
\text { (base: total Brazil } \\
\text { population) }\end{array}$ & 1.70 & 0.97 & 2.01 & 12.16 & 0.84 \\
\hline \multicolumn{6}{|l|}{ Diagnosed Pain } \\
\hline sample size (n) & 29 & 78 & 206 & 592 & 66 \\
\hline projected & 456,969 & 896,655 & $2,085,716$ & $6,356,350$ & 704,132 \\
\hline $\begin{array}{l}\text { projected \% (base: } \\
\text { experiencing pain) }\end{array}$ & 80.35 & 66.83 & 75.30 & 37.91 & 61.04 \\
\hline \multicolumn{6}{|l|}{ Treated for Pain } \\
\hline sample size (n) & 22 & 46 & 115 & 254 & 33 \\
\hline projected & 411,176 & 631,542 & $1,155,782$ & $2,963,585$ & 418,024 \\
\hline $\begin{array}{l}\text { projected } \% \text { (base: } \\
\text { diagnosed with pain) }\end{array}$ & 89.98 & 29.60 & 55.41 & 46.62 & 59.37 \\
\hline
\end{tabular}


those experiencing self-reported disease-specific pain symptoms, the most commonly diagnosed condition was neuropathic pain $(80.35 \%)$, with lower rates of diagnosis for fibromyalgia (75.30\%), rheumatoid arthritis or osteoarthritis pain $(66.83 \%)$, surgical or medical procedure pain $(61.04 \%)$, and back pain (37.91\%). Of those diagnosed with disease-specific pain conditions, the most commonly treated condition was neuropathic pain $(89.98 \%$, or $72.30 \%$ of those experiencing neuropathic pain), with lower rates of treatment for surgical or medical procedure pain (59.37\%), fibromyalgia (55.41\%), back pain $(46.62 \%$, or $17.67 \%$ of those experiencing back pain), and rheumatoid arthritis or osteoarthritis pain $(29.60 \%)$.

\section{Pain comparisons}

Except where noted otherwise, all comparisons described in this section were statistically significant, at two-tailed $\mathrm{p}<0.05$.

\section{Demographics}

In looking at the demographic characteristics of adults reporting disease-specific pain in Brazil compared with the non-disease specific painreporting control group, patients experiencing fibromyalgia and back pain were more likely to be women $(76.72 \%$ versus $50.74 \%$ and $58.15 \%$ versus $50.31 \%$, respectively; see Table 2). Back pain patients were younger than those not experiencing back pain (37.46 vs. 41.37 years). Patients experiencing neuropathic pain and arthritis pain were more likely than those not experiencing those pain specific states to be divorced $(36.97 \%$ versus $6.01 \%$ and $24.43 \%$ versus $5.03 \%$, respectively). In terms of income, those not experiencing fibromyalgia pain were more likely to report a lower income $(46.30 \%$ versus $33.46 \%$ at $\leq$ $\mathrm{R} \$ 2,000)$. SES and employment were not statistically significantly different across groups.

\section{Health profiles}

Fibromyalgia vs. no-fibromyalgia patients were more likely to report being overweight/obese $(62.20 \%$ versus $48.47 \%$ at $\mathrm{BMI} \geq 25)$ and to have a higher mean BMI (27.46 versus 25.79, respectively; Table 3).Arthritis patients experiencing vs. not experiencing arthritis pain, and those experiencing vs. not experiencing back pain, were more likely to drink alcohol $(66.14 \%$ versus $46.44 \%$ and $58.58 \%$ versus $52.71 \%$, respectively). Patients experiencing fibromyalgia and back pain were more likely to smoke than those not reporting the respective pain $(33.01 \%$ versus $19.99 \%$ and $24.19 \%$ versus $19.71 \%$; respectively). Patients experiencing back pain were less likely to exercise than those not experiencing back pain (mean days exercised per month was 5.31 versus 6.70 ).

\section{Comorbidities}

Comparing comorbidities across the respective groups, adults experiencing most types of pain were significantly more likely to report depression, sleep difficulties (including insomnia), anxiety, and a higher mean CCI, although arthritis patients did not report significantly more sleep difficulties compared with their reference group (Table 3 ).

\section{Health-related quality of life}

With respect to health status (SF-12v2 scores), adults experiencing neuropathic pain, fibromyalgia, back problems, and surgical or medical procedure pain were significantly more likely to have experienced lower physical (PCS) and health utilities scores (Table 4). Patients with arthritis and experiencing arthritis pain had lower mental (MCS) scores (41.21) than controls (45.86), as did patients with fibromyalgia, back pain, and surgery or medical procedure pain. Neuropathic pain patients experienced substantially lower PCS scores (33.19) than non-neuropathic pain patients (49.76), a difference greater than five times the suggested minimally important difference (MID) of 3 points $^{35}$. Arthritis patients with arthritis pain and neuropathic pain patients had significantly lower health utilities than controls $(0.591$ versus 0.671 and 0.555 versus 0.732 , respectively), both exceeding twice the MID of 0.03 points $^{36}$.

\section{Work impairment}

Patients experiencing neuropathic pain, fibromyalgia, back pain, and surgical or medical procedure pain had significantly higher impairment on all work productivity and activity-related impairment compared with the control groups (Table 4). For example, neuropathic pain patients were more likely than the non-neuropathic pain group to report substantially higher presenteeism and activity impairment $(59.65 \%$ versus $15.72 \%$ and $60.44 \%$ versus $20.97 \%$ respectively). Patients with arthritis and experiencing vs. not experiencing arthritis pain reported higher activity 


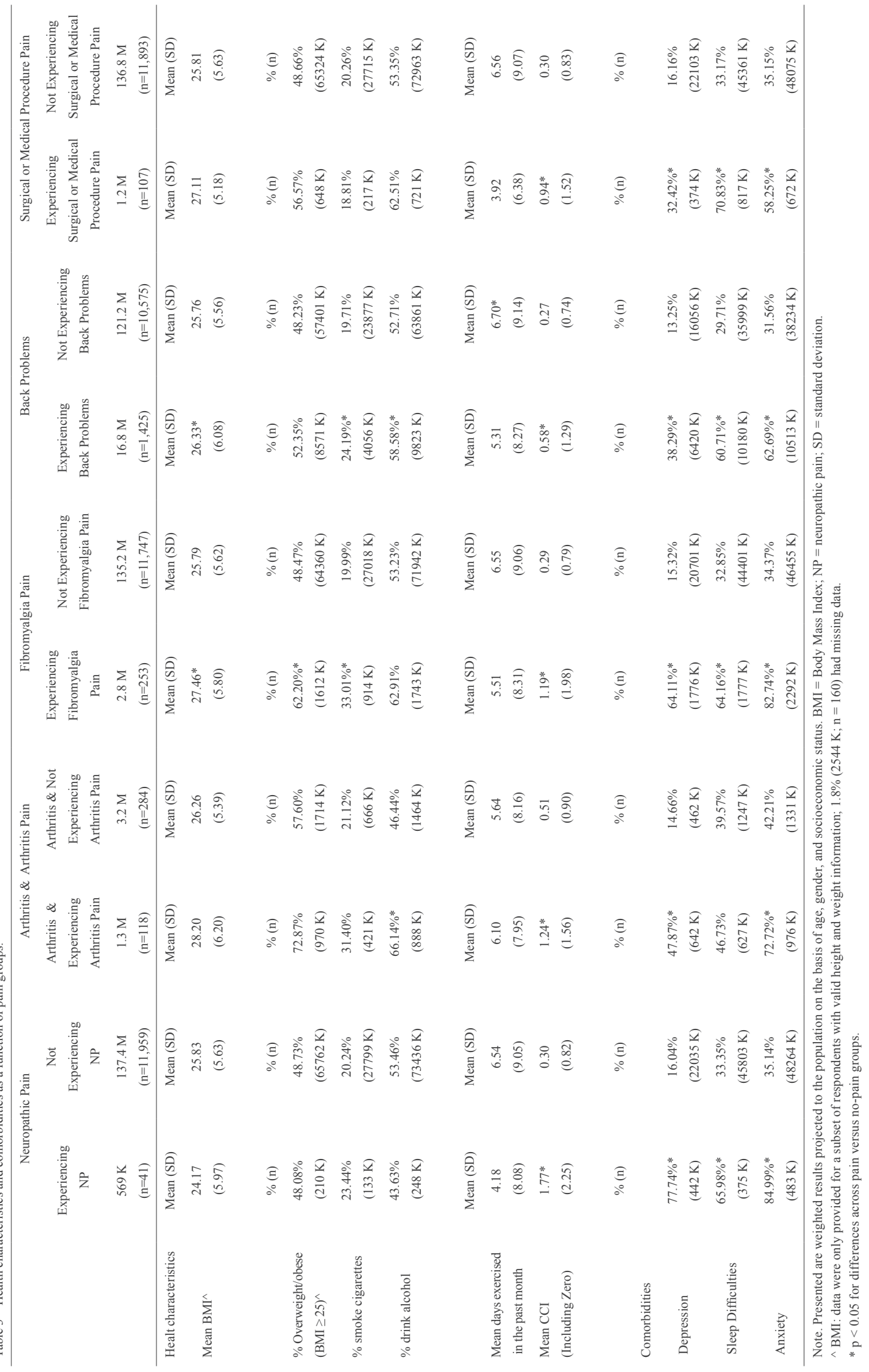




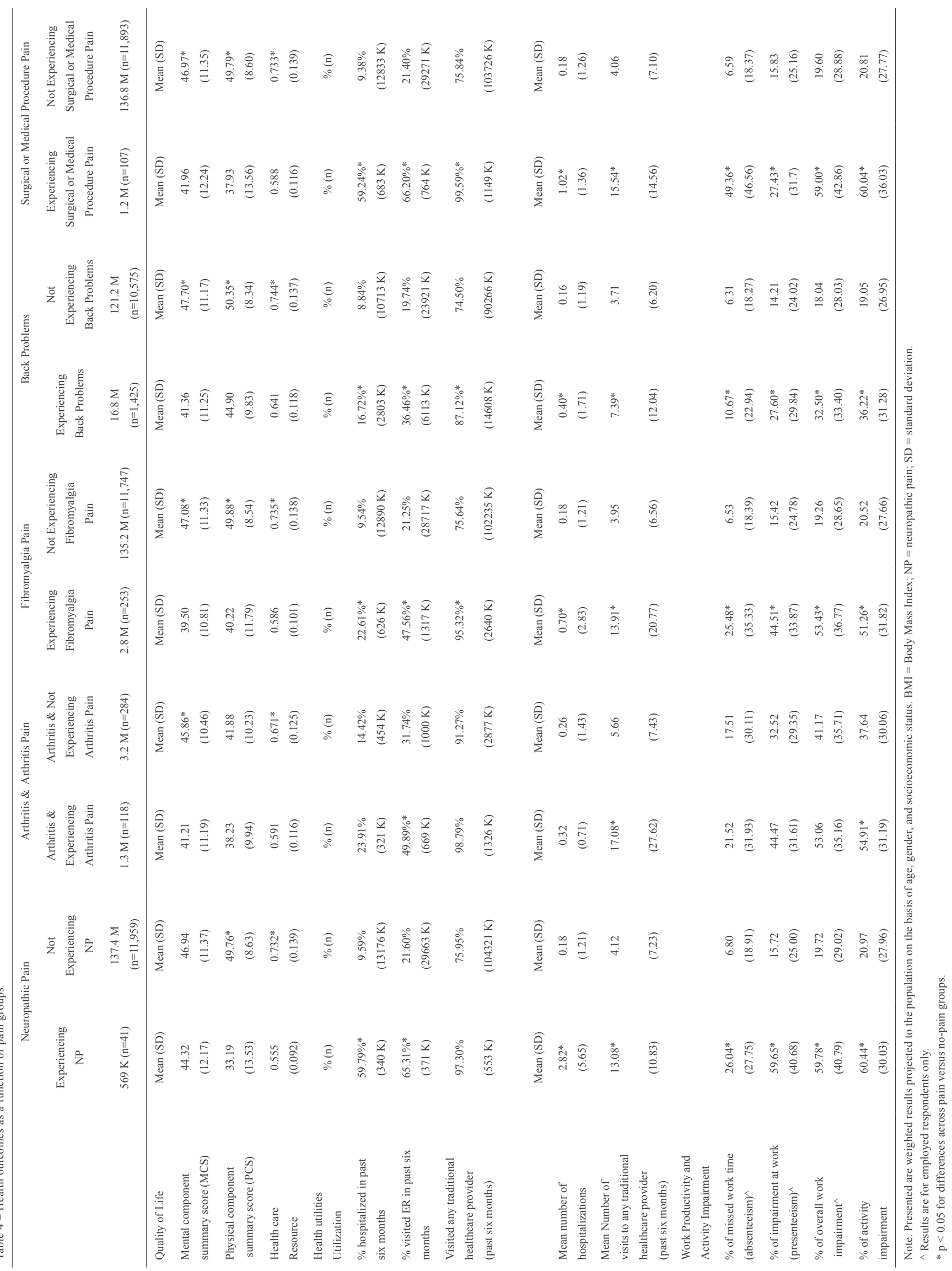


impairment (54.91\% versus 37.64\%) but did not differ significantly on the work productivity measures.

\section{Healthcare resource utilization}

Fibromyalgia, back pain, and surgery/medical procedure pain patients were more likely to have visited any traditional healthcare provider in the past six months; however, all pain vs. no-pain groups had significantly higher mean number of visits to any traditional healthcare provider (Table 4). All of the patients experiencing disease-specific pain states were more likely to have been hospitalized and visited the emergency room in the past six months, with the exception of patients experiencing arthritis pain, who did not have significantly more hospitalizations than arthritis patients not experiencing pain. Additionally, the aforementioned groups had a significantly higher number of hospitalizations.

\section{DISCUSSION}

Pain continues to cause a tremendous humanistic and economic burden worldwide. Despite its prevalence and impact, little research has examined the experience of pain outside of the U.S. and Europe, so the current study provides unique insight into the burden of pain in Brazilian adults. Consistent with previous findings, pain was reported by a significant number of adults, with back pain noted as the most common complaint ${ }^{5,7,8,11}$. Fibromyalgia and neuropathic pain were also reported by a substantial minority of survey respondents.

The current study also examined the rates of treatment associated with various pain conditions. A majority of individuals reporting diagnosis with neuropathic pain also reported receiving treatment; however, this rate was only $72 \%$ among those experiencing neuropathic pain, and the treatment rates dropped considerably for other conditions, with only $18 \%$ of those experiencing back pain receiving treatment. These differences in reported treatment may be associated with pain treatment practices, patients' treatment-seeking practices, condition severity, and the impact of the condition and its treatment on health-related outcomes. Back pain, for example, is highly prevalent, can often become chronic in nature, and can present a number of challenges in its management. Despite its prevalence and potential impact on healthrelated outcomes, relatively few individuals seek care for this condition ${ }^{37}$. Clinical guidance suggests that selfmanagement, with support as needed from health professionals, is preferable to invasive procedures (i.e., surgery) or overtreatment (i.e., excessive use of medication).
Therefore, those reporting no treatment for back pain may represent a combination of lack of access (i.e., not having seen a provider or being able to afford medication) and exhaustion and discontinuation of inadequate treatment options, despite ongoing pain. Importantly, both possibilities present unique challenges in the effective management of back pain (i.e., improved access, better therapies), thus warranting further investigation.

The low rate of reported treatment by those suffering from rheumatoid arthritis (RA) and osteoarthritis in the current study is also noteworthy. Once again, this is likely to represent a complex interaction between patient and provider attitudes towards care, and the degree of burden most often associated with these particular conditions. A recent review of the qualitative literature by Stack and colleagues reported a number of themes that may influence rates of care seeking for $\mathrm{RA}^{38}$. These included the impression that RA was a mild condition associated with aging, a lack of accurate knowledge concerning symptomatology, and a consistent tendency to minimize symptoms. Although it was reported that care was often sought once symptoms began affecting activity, each of these issues could be associated with delayed care-seeking or lack of follow-up with health care professionals. Similar findings have been reported in other research examining care-seeking decisions among RA sufferers ${ }^{39,40}$. Together with the current study findings, this may represent an important target for public health education, and warrants further investigation of barriers to treatment seeking in Brazilian adults diagnosed with RA.

A set of differences emerged in demographic and health behaviors between pain groups. Respondents reporting a diagnosis of fibromyalgia were more likely to be female, overweight or obese, and to smoke, compared with those not reporting this pain condition. This is consistent with previous findings that have found fibromyalgia more likely to be diagnosed in female patients ${ }^{41}$; however, there is a paucity of research regarding the association between this pain condition and health behaviors. A study by Weingarten and colleagues examined the prevalence and correlates of cigarette smoking in a sample of 984 individuals evaluated at a multidisciplinary fibromyalgia clinic, with smoking status reported to be associated with greater disease severity ${ }^{42}$. Previous research has also examined the role of excess weight in patients diagnosed with fibromyalgia. For example, Kim and colleagues noted that individuals with a BMI greater than 35 reported greater symptom severity, as well as impairments in quality of life domains ${ }^{43}$. The current study suggests similar associations between fibromyalgia 
and lifestyle behaviors and provides fertile ground for future exploration of their impact on disease management and severity.

Further differences were established in those respondents reporting back pain. Sufferers were more likely to be female, younger, consume alcohol, and smoke, and were less likely to exercise than those not reporting back pain. The management of a chronic condition such as back pain often necessitates a partnership between a patient and provider, with self-management and patient responsibility emphasized in clinical decision making, and health promoting behavior a critical component of care planning. The relationship between reported back pain and lifestyle behaviors in the current study raises possible concerns regarding patients' ability and willingness to engage in health promoting practices. Similarly, for example, Briggs and colleagues found that individuals with chronic lower back pain were more likely to report difficulty engaging in health behaviors than those without lower back pain ${ }^{44}$.

Pain conditions were associated with a range of important negative health outcomes. Other NHWSbased studies, using the same type of pain measure as in the current study, have seen similarly impressive burdens associated with pain ${ }^{2}$. Generally, adults experiencing pain were more likely to report depression, sleep difficulties, and anxiety, as well as higher rates of healthcare utilization than those not reporting pain. Importantly, those reporting back pain, fibromyalgia, and pain associated with medical or surgical conditions reported significantly more hospitalizations and visits to health care providers in the past six months than those not reporting these types of pain. Further, these same conditions were associated with consistent and significant impairments across all work and activity impairment indexes. Taken together, these results highlight the broad and significant impact that pain conditions can have on patients' lives, as well as the potential need for multidisciplinary approaches to address these conditions. The current study also provides insight into differences in the experience of patients based on their diagnosed condition, including variations in rates of treatment, comorbid conditions, and health behaviors. These results provide important and novel guidance in the development of effective pain management strategies in Brazil.

Limitations of the current study include smaller sample sizes, especially among arthritis patients, which may have limited our ability to detect differences associated with smaller effect sizes. Additionally, the causal impact of pain cannot be determined from a crosssectional study, even if several measured variables did not differ significantly across groups, as there may be other unmeasured differences across groups that correlate with the outcomes of interest. Future studies should examine the longitudinal impact of pain, controlling for possible confounds.

The current study highlights the prevalence and burden of different pain conditions, providing important insight into the experience of those with pain in Brazil. The significant number of individuals reporting pain, despite these conditions being under-diagnosed and under-treated, further emphasizes the challenge in providing effective and safe pain management. Across various conditions, pain was associated with a range of negative outcomes, including impaired quality of life, increased healthcare utilization, and impairments in work productivity and daily activities. These results further emphasize the far-reaching impact of pain and the ongoing need for improvements in our understanding of this domain of medical care.

\section{Disclosure}

Amir Goren, Hillary Gross, and Abhishek Pandey are employees of Kantar Health who were paid consultants to Pfizer in connection with the development of this manuscript. Ronaldo Fujii and Joaquin Mould-Quevedo are full-time employees of Pfizer Inc. Editorial support and literature review was provided by Errol Philip, a consultant to Kantar Health, and was funded by Pfizer.

\section{ACKNOWLEDGMENTS}

The authors would like to acknowledge Errol J. Philip, $\mathrm{PhD}$, who provided support with literature review and manuscript editing on behalf of Kantar Health, with funding from Pfizer, Inc.

\section{REFERENCES}

1. Langley P, Muller-Schwefe G, Nicolaou A, et al. The societal impact of pain in the European Union: health-related quality of life and healthcare resource utilization. J Med Econ. 2010;13(3):571-81.

2. Langley PC. The prevalence, correlates and treatment of pain in the European Union. Curr Med Res Opin. 2011;27(2):463-80.

3. Langley PC, Ruiz-Iban MA, Molina JT, et al. The prevalence, correlates and treatment of pain in Spain. J Med Econ. 2011;14(3):367-80.

4. Gerdle B, Bjork J, Coster L, et al. Prevalence of widespread pain and associations with work status: a population study. BMC Musculoskelet Disord. 2008;9:102. 
5. Hardt J, Jacobsen C, Goldberg J, et al. Prevalence of chronic pain in a representative sample in the United States. Pain Med. 2008;9(7):803-12.

6. Reid KJ, Harker J, Bala MM, et al. Epidemiology of chronic non-cancer pain in Europe: narrative review of prevalence, pain treatments and pain impact. Curr Med Res Opin. 2011;27(2):449-62.

7. Breivik H, Collett B, Ventafridda V, et al. Survey of chronic pain in Europe: prevalence, impact on daily life, and treatment. Eur J Pain. 2006;10(4):287-333.

8. Schiller JS, Lucas JW, Ward BW, et al. Summary health statistics for U.S. adults: National Health Interview Survey, 2010. Vital Health Stat. 2012;10:252.

9. van den Beuken-van Everdingen MH, de Rijke JM, Kessels AG, et al. Prevalence of pain in patients with cancer: a systematic review of the past 40 years. Ann Oncol. 2007;18(9):1437-49.

10. Institute of Medicine. Institute of Medicine Report from the Committee on Advancing Pain Research, Care, and Education: Relieving Pain in America, A Blueprint for Transforming Prevention, Care, Education and Research. The National Academies Press, 2011.

11. Tsang A, Von Korff M, Lee S, et al. Common chronic pain conditions in developed and developing countries: gender and age differences and comorbidity with depression-anxiety disorders. J Pain. 2008;9(10):883-91.

12. Green CR, Hart-Johnson T, Loeffler DR. Cancerrelated chronic pain: examining quality of life in diverse cancer survivors. Cancer. 2011;117(9):1994-2003.

13. Tuzun EH. Quality of life in chronic musculoskeletal pain. Best Pract Res Clin Rheumatol. 2007;21(3):567-79. 14. Bair MJ, Robinson RL, Katon W, et al. Depression and pain comorbidity: a literature review. Arch Intern Med. 2003;163(20):2433-45.

15. Davis JA, Robinson RL, Le TK, et al. Incidence and impact of pain conditions and comorbid illnesses. J Pain Res. 2011;4:331-45.

16. Classification of chronic pain. Descriptions of chronic pain syndromes and definitions of pain terms. Prepared by the International Association for the Study of Pain, Subcommittee on Taxonomy. Pain Suppl. 1986;3:S1-226.

17. Martell BA, O'Connor PG, Kerns RD, et al. Systematic review: opioid treatment for chronic back pain: prevalence, efficacy, and association with addiction. Ann Intern Med. 2007;146(2):116-27.

18. Deandrea S, Montanari M, Moja L, et al. Prevalence of undertreatment in cancer pain. A review of published literature. Ann Oncol. 2008;19(12):1985-91.

19. Fairchild A. Under-treatment of cancer pain. Curr Opin Support Palliat Care. 2010;4(1):11-5.
20. Narayan MC. Culture's effects on pain assessment and management. Am J Nurs. 2010;110(4):38-47.

21. De Vitta A, Martinez MG, Piza NT, et al. Prevalence of lower back pain and associated factors in students. Cad Saude Publica. 2011;27(8):1520-8.

22. Almeida JG, Kurita GP, Braga PE, et al. Chronic pain in schizophrenic patients: prevalence and characteristics. Cad Saude Publica. 2010;26(3):591-602.

23. Kreling MC, da Cruz DA, Pimenta CA. Prevalence of chronic pain in adult workers. Rev Bras Enferm. 2006;59(4):509-13.

24. World Medical Association Declaration of Helsinki Ethical Principles for Medical Research Involving Human Subjects Bulletin of the World Health Organization, 2001;79(4):373-4.

25. Langley P, Muller-Schwerfe G, Nicolaou A, et al. The societal impact of pain in the European Union: health-related quality of life and healthcare resource utilization. J Med Econ. 2010;13(3):571-81.

26. Associação Brasileira de Empresas de Pesquisa. Critério de Classificação Econômica Brasil. 2008.

27. Charlson ME, Pompei P, Ales KL, et al. A new method of classifying prognostic comorbidity in longitudinal studies: development and validation. J Chronic Dis. 1987;40:373-83.

28. Laguardia J, Campos MR, Travassos CM, et al. Psychometric evaluation of the SF-36 (v.2) questionnaire in a probability sample of Brazilian households: results of the survey Pesquisa Dimensoes Sociais das Desigualdades (PDSD), Brazil, 2008. Health Qual Life Outcomes. 2011;9:61.

29. Ware JJ, Kosinski M, Turner-Bowker D, et al. User's manual for the SF-12v2 ${ }^{\mathrm{TM}}$ health survey with a supplement documenting SF-12® health survey. Lincoln: QualityMetric Incorporated, 2001.

30. Cavalheiro LM, Gil JA, Goncalves RS, et al. Measuring the pain impact in adults with a chronic pain condition: adaptation and validation of the Pain Impact Questionnaire (PIQ-6) to the Portuguese culture. Pain Med. 2011;12(10):1538-43.

31. Ferreira-Valente MA, Pais-Ribeiro JL, Jensen MP. Psychometric properties of the portuguese version of the Pain Self-Efficacy Questionnaire. Acta Reumatol Port. 2011;36(3):260-7.

32. Reilly MC, Zbrozek AS, Dukes EM. The validity and reproducibility of a work productivity and activity impairment instrument. Pharmacoeconomics. 1993;4(5):353-65.

33. Ciconelli RM, Soarez PC, Kowalski CC, et al. The Brazilian Portuguese version of the Work Productivity and Activity Impairment: General Health (WPAI-GH) 
Questionnaire. Sao Paulo Med J. 2006;124(6):325-32. 34. Fletcher MJ, Upton J, Taylor-Fishwick J, et al. COPD uncovered: an international survey on the impact of chronic obstructive pulmonary disease [COPD] on a working age population. BMC Public Health. 2011;11:612.

35. Hays RD, Morales LS. The RAND-36 measure of health-related quality of life. Ann Med. 2001;33(5):350-7.

36. Walters SJ, Brazier JE. Comparison of the minimally important difference for two health state utility measures: EQ-5D and SF-6D. Qual Life Res. 2005;14(6):1523-32.

37. Balague F, Mannion AF, Pellise F, et al. Non-specific low back pain. Lancet. 2012;379(9814):482-91.

38. Stack RJ, Shaw K, Mallen C, et al. Delays in help seeking at the onset of the symptoms of rheumatoid arthritis: a systematic synthesis of qualitative literature. Ann Rheum Dis. 2012;71(4):493-7.

39. Sheppard J, Kumar K, Buckley CD, et al. 'I just thought it was normal aches and pains': a qualitative study of decision-making processes in patients with early rheumatoid arthritis. Rheumatology (Oxford). 2008;47(10):1577-82.

40. Kumar K, Daley E, Carruthers DM, et al. Delay in presentation to primary care physicians is the main reason why patients with rheumatoid arthritis are seen late by rheumatologists. Rheumatology (Oxford). 2007;46(9):1438-40.

41. McNally JD, Matheson DA, Bakowsky VS. The epidemiology of self-reported fibromyalgia in Canada. Chronic Dis Can. 2006;27(1):9-16.

42. Weingarten TN, Podduturu VR, Hooten WM, et al. Impact of tobacco use in patients presenting to a multidisciplinary outpatient treatment program for fibromyalgia. Clin J Pain. 2009;25(1):39-43.

43. Kim CH, Luedtke CA, Vincent A, et al. Association of body mass index with symptom severity and quality of life in patients with fibromyalgia. Arthritis Care Res (Hoboken). 2012;64(2):222-8.

44. Briggs AM, Jordan JE, O'Sullivan PB, et al. Individuals with chronic low back pain have greater difficulty in engaging in positive lifestyle behaviours than those without back pain: an assessment of health literacy. BMC Musculoskelet Disord. 2011;12:161

Submitted in November 15, 2012.

Accepted for publication in December 03, 2012. 